\title{
Using Logistic Regress Model for Analysis of Sports Consumption Behavior among Adolescents
}

\author{
Hongjiang Wang \\ Chengdu Sport University, Chengdu, 610041, China
}

Keywords: Logistic regress model; sport consumption; adolescents; Chengdu.

\begin{abstract}
The purpose of this study was to explore the relations between sports consumption behavior and influential factors among different adolescents in Chengdu. 2830 students in primary and secondary schools from traditional specialist schools and common schools participated in this survey. After analyzing the data collected in questionnaires, the findings showed that (a) constraints of sports consumption behaviors of adolescents in Chengdu are concentrated in six major aspects, they are economic pressure, health behavior, value perception, sports policy, fitness conditions and academic pressure,(b) as far as range of influence is concerned, factors of health behavior and fitness condition have the most extensive range of influence, and in regard of degree of influence, health behavior factor is most powerful, and (c) traditional specialist schools have favorable sports policy, better value perception and superior fitness condition than schools.
\end{abstract}

\section{Introduction}

Sports consumption behavior have been studies by many researchers. For example, Kiremitci et al. examined the psychometric properties of the Turkish version of Sport Consumption Behavior Intention Scale. The results of confirmatory factor analysis applied to the data have revealed that the data set was in good fit with the three factor structure formed[1]. Suk-Kyu Kim et al. examined the relationship between spectator social motivations and sport consumption behavior in the context of Formula One motor-racing events [2]. Byon et al. examined the structural relationship of core service quality and peripheral service quality factors to the consumption of professional team sport games while considering the mediating influence of perceived value [3]. Li-Shiue Gau et al. examined the values associated with sports attitudes and consumption behavior [4]. Trail et al. develop the motivation scale for sport consumption to measure the motivations behind sport spectator consumption behavior [5] . The research proceeds with sports consumption behaviors and constraints of adolescents in Chengdu, a western city in China, and aims to find out key factors constraining sports consumption of adolescents in Chengdu based on analysis on current situation and constraints, so as to effectively develop sports consumption market for adolescents in western area, properly understand and guide its sports consumption characteristics in a timely manner, and provide significant references for governmental macroeconomic regulation and control and decision-making of enterprises and merchants.

\section{Subjects and methods}

\subsection{Subjects}

Stratified sampling is adopted according to purpose of research: primary school group 1, primary school group 2, junior school group and high school group, a total of 4 groups. Each group is classified into 2 types, i.e. traditional specialist school and non-specialist school. District and county schools in or close to main urban area of Chengdu are taken as research objects, and sports bureaus of each district and county shall survey and examine physical education of all junior and primary schools to ensure that primary school groups, junior school group and high school group meet general purpose of the research, and then questionnaire issuing unit and sample size shall be determined by random sampling. 


\subsection{Questionnaire method}

A self-designed questionnaire named Sports Consumption Behaviors and Influential Factors of Adolescents in Chengdu shall be issued and recovered as soon as informants finishing it. 3000 questionnaires are issued, with effective recovery rate of $93.4 \%$ in regardless of 197 invalid ones. The questionnaire is consist of two parts: part I is about current situation of adolescents' sports consumption, which includes 6 major items and 18 small items, involving demographic variables, sports consumption varieties and sport consumption awareness of adolescents; part II is about factors hindering adolescents' sports consumption, which are prepared by using five-point scale, including 21 questions.

\subsection{Statistics method}

SPSS16.0 was used in this study, one-way ANOVA, factor analysis, ordinal logistic regression analysis were used. Significance level was set at $\mathrm{a}=0.05$.

\section{Result and Analysis}

\subsection{Extraction and designation of influential factors of sport consumption}

Values of 21 original variables are $0.825>0.5$ in KMO Test, meeting basic requirements for factor analysis; chi-square value $\mathrm{X} 2=78.88, \mathrm{P}<0.01$ in Bartlett Test, further affirming that 21 original variables are suitable for factor analysis. PCA is used to extract common factors, and characteristic roots of first 6 components among 21 are respectively 8.15, 6.17, 4.69, 3.25, 2.14 and 1.88 (all exceed 1 ) Interpretation degree of variation of them to 21 original variables are respectively $23.91 \%$, $18.10 \%, 13.76 \%, 9.54 \%, 6.28 \%$ and $5.54 \%$, and progressive rate of contribution reaches $77.11 \%>70 \%$, therefore, the research regards it basically rational to extract first 6 principal components as common factors. Loading coefficients of 21 variables on 6 common factors after rotation of factors clearly indicates that: common factor 1 (F1) is mainly controlled by A10, A6, A2 and A14, which are involved in heavy family economic pressure, so adolescents are not capable of participating in physical training and purchase of related sports equipment and clothing of charging stadiums, therefore, F1 is named as economic pressure factor; common factor 2 (F2) is mainly controlled by A8, A12, A16 and A4, which are involved in adolescents' health behaviors, e.g. sedentariness, diet, sleep and smoking, therefore, F2 is named as health behavior factor; common factor 3 (F3) is mainly controlled by A19, A18 A21 and A17, which are involved in significance and value of physical exercise and relationship between health and exercise, therefore, F3 is named as value perception factor; common factor 4 (F4) is mainly controlled by A5, A13 and A20, which are involved in sports policy, therefore, F4 is named as policy factor; common factor 5 (F5) is mainly controlled by A15, A11 and A7, which are involved in guidance of physical exercise, environment, place and other hardware facilities, therefore, F5 is named as fitness condition factor; common factor 6 (F6) is mainly controlled by A1, A9 and A3, which are involved in problems of occupancy of PE, heavy learning tasks and squeeze of spare time, therefore, F6 is named as academic pressure factor.

\subsection{Correlation analysis on influential factors in sport consumption and constraint}

Establishment of polytomous logistic regression model. The research takes 6 major influential factors hindering adolescents' sport consumption as independent variables, and 5 mainstream directions - sports consumption attitude, substance consumption, consumption value, spectator-sports consumption and sum of consumption as dependent variables to establish respective regression models to further discuss degree of influence of hindering factors do to adolescents' sport consumption behaviors.

Here, causal relationship of sum of consumption to 6 hindering factors is set as an example for modeling, which shares the same construction idea with the other 4 models. Annual sum of consumption is regarded as variable $\mathrm{Y}$, which is divided into 5 levels, i.e. "lower than RMB 200", "RMB 200-500", "RMB 500-1000", "RMB1000- 1500" and "more than 1500".Corresponding probabilities are supposed to be $\mathrm{P} 1, \mathrm{P} 2, \mathrm{P} 3, \mathrm{P} 4$ and $\mathrm{P} 5$, and meet the conditions $\mathrm{P} 1+\mathrm{P} 2+\mathrm{P} 3+\mathrm{P} 4+\mathrm{P} 5=1$. Based on these probabilities, $\mathrm{n}$ independent observation objects will be distributed to respective types, 
and distribution of objects in $\mathrm{J}$ types shall be subject to multinomial distribution.6 hindering factors are denoted as $\mathrm{Ak}(\mathrm{K}=1,2,3 \ldots \ldots 6), \alpha \mathrm{j}$ and bjk are respectively constant term of Type $\mathrm{j}$ and explanatory variable parameter, and polytomous logistic model can be expressed as follows:

$$
\ln \left(P_{j} / P_{J}\right)=\alpha_{j}+b_{j 1} A_{1}+b_{j 2} A_{2}+b_{j 3} A_{3}+b_{j 4} A_{4}+b_{j 5} A_{5}+b_{j 6} A_{6} \cdots \cdots
$$

In which A1, A2, A3, A4, A5 and A6 are 6 common factors. In the above equation, the last type $\mathrm{J}$ ("lower than RMB 100" in this question) is set as base line, and regression model is built between each reaction type $\mathrm{j}$ and base line type $\mathrm{J}$. Therefore, this model is also called baseline-category logistic model, which shall estimate (J-1) binary response logit models simultaneously. It has a wide application range and high flexibility, so it is also called generalized logit model. When odds ratio $(\mathrm{OR})$ is introduced in the regression model, expression is as follows:

$$
P_{j} / P_{J}=0=\exp \left(\alpha_{j}+b_{j 1} A_{1}+b_{j 2} A_{2}+b_{j 3} A_{3}+b_{j 4} A_{4}+b_{j 5} A_{5}+b_{j 6} A_{6}\right)
$$

It can be seen from the expression (1) that, among sum of consumption of adolescents, advantage of $\mathrm{j}$ is as follows compared to type $\mathrm{J}$ :

$$
P_{j} / P_{J}=O=\exp \left(\alpha_{j}+b_{j 1} A_{1}+b_{j 2} A_{2}+b_{j 3} A_{3}+b_{j 4} A_{4}+b_{j 5} A_{5}+b_{j 6} A_{6}\right)
$$

Where exp is exponent of natural logarithm log base, and bjk indicates average variation of log odds when one certain independent variable $\mathrm{Aj}$ changes a unit value and other independent variables remain the same. Generally, $\mathrm{OR}>1$ indicates favorable factor and $\mathrm{OR}<1$ indicates negative factor; $\mathrm{OR}=1$ indicates no relation to dependent variables.

Test of logistic regression model. Likelihood ratios, values of chi-square X2 and corresponding probability values of 5 models about adolescents' sports consumption behaviors can be seen from Table 1. From the perspective of overall test results, all 5 models are statistically significant; from the perspective of test result of goodness of fit of models, all corresponding P values of 5 models are over 0.05 , which further affirms acceptability of imitative effect of models.

Table 1. Effect of fit of models

\begin{tabular}{ccc}
\hline Models & $\begin{array}{c}\text { Global test for model } \\
\text { Likelihood Ratio }\end{array}$ & $\begin{array}{c}\text { Goodness of Fit test for model } \\
\text { Coefficient of determination (Pearson X2) }\end{array}$ \\
\hline Model 1: Attitude model & $234.14 ; \mathrm{P}=0.00<0.05$ & $2511.12 ; \mathrm{P}=0.27>0.05$ \\
Model 2: Physical model & $178.31 ; \mathrm{P}=0.00<0.05$ & $3127.16 ; \mathrm{P}=0.41>0.05$ \\
Model 3: Value Model & $309.25 ; \mathrm{P}=0.00<0.05$ & $3571.41 ; \mathrm{P}=0.51>0.05$ \\
Model 4: Show-oriented & $227.24 ; \mathrm{P}=0.00<0.05$ & $2397.54 ; \mathrm{P}=0.61>0.05$ \\
Model 5: Fee model & $321.15 ; \mathrm{P}=0.00<0.05$ & $3065.12 ; \mathrm{P}=0.47>0.05$ \\
\hline
\end{tabular}

OR analysis on influence of six major hindering factors to sports consumption behaviors. Table 2 indicates that: (1) Health behavior and fitness condition factor have the most extensive influence, reaching significance level in 5 models $(\mathrm{P}<0.05)$. It can be seen from the perspective of degree of influence that, with each good change of level of health behavior, or elevation of level of fitness condition, number of adolescents whose sports consumption attitude changing from "unwilling" to "willing" will be 1.39 and 1.36 times of the original number respectively, number of people who changed from "never use" to "use" substance consumption mode will rise to 1.71 and 1.75 times of the original number respectively, number of people whose perception towards sports consumption value changing from "not worthy" to "worthy" will rise to 1.68 and 1.58 times of the original number respectively, number of people who changed from "never use" to "use" spectator-sports consumption mode will rise to 1.52 and 1.39 times of the original number respectively, and number of people whose sum of consumption changing from "lower that RMB 100" to "no less than RMB 400" will rise to 1.87 and 1.28 times of the original number respectively; (2) Economic pressure factor also has a great effect on adolescents' sports consumption behaviors, reaching significance level in 4 models out of $5(\mathrm{P}<0.05)$. With elevation of one level of economic pressure, number of adolescents whose sports consumption attitude changing from "unwilling" to "willing" will decrease 0.86 times of the original 
number, number of people who changed from "never use" to "use" substance consumption mode will reduce to 0.75 times of the original number, number of people who changed from "never use" to "use" spectator-sports consumption mode will reduce to 0.81 times of the original number, and number of people whose sum of consumption changing from "lower that RMB 100" to "no less than RMB 400" will reduce to 0.83 times of the original number; (3) School sports policy factor also has an extensive influence, reaching significance level in 3 models out of $5(\mathrm{P}<0.05)$. With one unit value elevation of school sports policy, number of adolescents whose sports consumption attitude changing from "unwilling" to "willing" will rise to 1.41 times of the original number, number of people who changed from "never use" to "use" substance consumption mode will rise to 1.36 times of the original number, and number of people whose perception towards sports consumption value changing from "not worthy" to "worthy" will rise to 1.25 times of the original number; and (4) Physical exercise value perception factor has a relative weak effect, only 2 in 5 models reaching significance level $(\mathrm{P}<0.05)$. It influences adolescents' attitude and value perception toward sports consumption. With elevation of one level of adolescents' physical exercise value perception, number of adolescents whose sports consumption attitude changing from "unwilling" to "willing" will rise to 1.29 times of the original number, and number of people whose perception towards sports consumption value changing from "not worthy" to "worthy" will rise to 1.31 times of the original number.

Table 2. Parameters statistics of impacts of 6 major common factors on 5 models $(\operatorname{Exp}(b)=O R)$

\begin{tabular}{|c|c|c|c|c|c|c|c|c|c|c|c|c|c|c|c|}
\hline \multirow{3}{*}{$\begin{array}{c}\text { Factors } \\
\\
\\
\text { Economic } \\
\text { pressure } \\
\text { fprprepres }\end{array}$} & \multicolumn{3}{|c|}{$\begin{array}{l}\text { Model 1: Attitude,OR } \\
\text { ="Willing / } \\
\text { "unwilling" }\end{array}$} & \multicolumn{3}{|c|}{$\begin{array}{l}\text { Model 2: Physical, } \\
\text { OR="purchased"/"n } \\
\text { ot purchased" }\end{array}$} & \multicolumn{3}{|c|}{$\begin{array}{l}\text { Model 3: } \\
\text { value, } \mathrm{OR}=\text { "“Wo } \\
\text { rthy "/"No } \\
\text { worthy" }\end{array}$} & \multicolumn{3}{|c|}{$\begin{array}{c}\text { Model } 4: \\
\text { show-oriented } \\
\text { OR="purchased } \\
\text { "/"“not } \\
\text { purchased" }\end{array}$} & \multicolumn{3}{|c|}{$\begin{array}{l}\text { Model5: Fee } \\
\text { OR="400 or } \\
\text { above"/“"100or } \\
\text { less" }\end{array}$} \\
\hline & \multicolumn{2}{|c|}{$\begin{array}{c}\operatorname{Exp}(b) \\
\text { P值 }\end{array}$} & \multirow{2}{*}{$\begin{array}{l}\mathrm{Si} \\
\mathrm{g} . \\
*\end{array}$} & \multirow{2}{*}{$\begin{array}{c}\operatorname{Exp}(b) \\
0.75\end{array}$} & \multirow{2}{*}{$\begin{array}{c}P \\
0.0 \\
0\end{array}$} & \multirow{2}{*}{$\begin{array}{c}\text { Sig } \\
\text {.检 } \\
*\end{array}$} & \multicolumn{2}{|c|}{$\operatorname{Exp}(b) P$} & \multirow[t]{2}{*}{ Sig } & \multicolumn{2}{|c|}{$\begin{array}{c}\operatorname{Exp}(b) P \\
\text { 值 }\end{array}$} & \multirow{2}{*}{$\begin{array}{c}\text { Sig } \\
\cdot \\
*\end{array}$} & \multicolumn{2}{|c|}{$\begin{array}{c}\operatorname{Exp}(b) P \\
\quad \text { 值 }\end{array}$} & \multirow{2}{*}{$\begin{array}{c}\text { Sig } \\
\cdot \\
*\end{array}$} \\
\hline & 0.86 & $\begin{array}{c}0.0 \\
0\end{array}$ & & & & & $\begin{array}{c}0.9 \\
6\end{array}$ & $\begin{array}{c}0.3 \\
7\end{array}$ & & $\begin{array}{c}0.8 \\
1\end{array}$ & $\begin{array}{c}0.0 \\
0\end{array}$ & & $\begin{array}{c}0.8 \\
3\end{array}$ & $\begin{array}{c}0.0 \\
0\end{array}$ & \\
\hline $\begin{array}{c}\text { Health } \\
\text { behavior } \\
\text { Attitutebe }\end{array}$ & 1.39 & $\begin{array}{c}0.0 \\
0\end{array}$ & $*$ & 1.71 & $\begin{array}{c}0.0 \\
0\end{array}$ & $*$ & $\begin{array}{c}1.6 \\
8\end{array}$ & $\begin{array}{c}0.0 \\
0\end{array}$ & $*$ & $\begin{array}{c}1.5 \\
2\end{array}$ & $\begin{array}{c}0.0 \\
0\end{array}$ & $*$ & $\begin{array}{c}1.8 \\
7\end{array}$ & $\begin{array}{c}0.0 \\
0\end{array}$ & $*$ \\
\hline $\begin{array}{l}\text { Value } \\
\text { cognitive }\end{array}$ & 1.29 & $\begin{array}{c}0.0 \\
3\end{array}$ & $*$ & 1.13 & $\begin{array}{c}0.1 \\
2\end{array}$ & & $\begin{array}{c}1.3 \\
1\end{array}$ & $\begin{array}{c}0.0 \\
0\end{array}$ & $*$ & $\begin{array}{c}1.0 \\
2\end{array}$ & $\begin{array}{c}0.9 \\
1\end{array}$ & & $\begin{array}{c}0.8 \\
6\end{array}$ & $\begin{array}{c}0.1 \\
6\end{array}$ & \\
\hline $\begin{array}{l}\text { Sports } \\
\text { policy }\end{array}$ & 1.41 & $\begin{array}{c}0.0 \\
0\end{array}$ & $*$ & 1.36 & $\begin{array}{c}0.0 \\
0\end{array}$ & * & $\begin{array}{c}1.2 \\
5\end{array}$ & $\begin{array}{c}0.0 \\
0\end{array}$ & $*$ & $\begin{array}{c}1.0 \\
7 \\
\end{array}$ & $\begin{array}{c}0.5 \\
5 \\
\end{array}$ & & $\begin{array}{c}1.0 \\
2 \\
\end{array}$ & $\begin{array}{c}0.8 \\
4\end{array}$ & \\
\hline $\begin{array}{l}\text { Fitness } \\
\text { condition } \\
\text { condition }\end{array}$ & 1.36 & $\begin{array}{c}0.0 \\
0\end{array}$ & $*$ & 1.75 & $\begin{array}{c}0.0 \\
0\end{array}$ & $*$ & $\begin{array}{c}1.5 \\
8\end{array}$ & $\begin{array}{c}0.0 \\
0\end{array}$ & $*$ & $\begin{array}{c}1.3 \\
9\end{array}$ & $\begin{array}{c}0.0 \\
0\end{array}$ & $*$ & $\begin{array}{c}1.2 \\
8\end{array}$ & $\begin{array}{c}0.0 \\
1\end{array}$ & * \\
\hline $\begin{array}{l}\text { Academic } \\
\text { pressure } \\
\text { pressureap }\end{array}$ & 1.79 & $\begin{array}{c}0.0 \\
0\end{array}$ & $*$ & 1.28 & $\begin{array}{c}0.0 \\
0\end{array}$ & $*$ & $\begin{array}{c}1.3 \\
4\end{array}$ & $\begin{array}{c}0.0 \\
1\end{array}$ & $*$ & $\begin{array}{c}1.1 \\
2\end{array}$ & $\begin{array}{c}0.1 \\
6\end{array}$ & & $\begin{array}{c}1.1 \\
3\end{array}$ & $\begin{array}{c}0.1 \\
9\end{array}$ & \\
\hline
\end{tabular}

\section{Conclusion}

(1) Constraints of sports consumption behaviors of adolescents in Chengdu are concentrated in six major aspects. In order of extent of constraints, they are economic pressure, health behavior, value perception, sports policy, fitness conditions and academic pressure. (2) As far as range of influence is concerned, factors of health behavior and fitness condition have the most extensive range of influence, reaching significance level in 5 models; economic pressure factor follows closely, reaching 
significance level in 4 models out of 5; sports policy factor ranks 3, and academic pressure has the least effect, only reaching significance level in 2 models out of 5. (3) In regard of degree of influence, health behavior factor is most powerful, and its ORs to adolescents' sports consumption attitudes, substance consumption, consumption value, spectator-sports consumption and sum of consumption are 1.39, 1.71, 1.68, 1.52 and 1.87 respectively; second is fitness condition, and its corresponding five ORs are $1.36,1.75,1.58,1.39$ and 1.28; while value perception has relative small effect. (4) Traditional specialist schools have favorable sports policy, better value perception and superior fitness condition than common schools, and no difference in health behavior and academic pressure; for adolescents in different grades, primary school students have the greatest health behavior, superior fitness condition and least academic pressure; junior school students have the least economic pressure and the most favorable sports policy; high school students have the best value perception, but bear the heaviest economic pressure and academic pressure, the poorest sports policy and fitness condition.

\section{Acknowledgements}

This study was supported by Ministry of Education funding project of Humanities and Social Science (13YJA890027).

\section{References}

[1]. Kiremitci, Olcay; Demiray, Erdinç; Gençer, R. Timuçin; Aycan, Ali, Pamukkale. Assessing the Validity and Reliability of the sport consumption behavior scale on Turkish football spectators. Journal of Sport Sciences 2014, Vol. 5 Issue 2, p11

[2]. Suk-Kyu Kim; Byon, Kevink.; Jae-Gu Yu; Zhang, James J.; Chong Kim, Social motivations and consumption behavior of spectators attending a formula one event. Social Behavior \& Personality: an international journal 2013, Vol. 41 Issue 8, p1359

[3]. Byon, Kevin K.; Zhang, James J.; Baker, Thomas A., Impact of core and peripheral service quality on consumption behavior of professional team sport spectators as mediated by perceived value. European Sport Management Quarterly Apr2013, Vol. 13 Issue 2, p232

[4]. Li-Shiue Gau; Korzenny, Felipe, An examination of values associated with sports attitude and consumption behavior: An exploratory study.Social Behavior \& Personality: an international journal 2009, Vol. 37 Issue 3, p299

[5]. Trail, Galen T.; James, Jeffrey D., the Motivation Scale for Sport Consumption: Assessment of the Scale's Psychometric Properties. Journal of Sport Behavior Mar2001, Vol. 24 Issue 1, p108 